\title{
The Marine Guanidine Alkaloid Crambescidin 816 Induces Calcium Influx and Cytotoxicity in Primary Cultures of Cortical Neurons through Glutamate Receptors
}

\author{
Aida G. Mendez, ${ }^{\dagger}$ Andrea Boente Juncal, ${ }^{\dagger}$ Siguara B. L. Silva, ${ }^{\ddagger} \perp$ Olivier P. Thomas, ${ }^{\ddagger}, \|_{\odot}$ \\ Víctor Martín Vázquez,,$^{\dagger}$ Amparo Alfonso, ${ }^{\dagger}$ Mercedes R. Vieytes, ${ }^{\S}$ Carmen Vale, ${ }^{*}{ }^{\dagger}$ (i) \\ and Luís M. Botana*,† \\ ${ }^{\dagger}$ Departamento de Farmacología, Facultad de Veterinaria, Universidad de Santiago de Compostela, Lugo 27002, Spain \\ ${ }^{\ddagger}$ Geoazur, UMR Université Nice Sophia Antipolis-CNRS-IRD-OCA, 06560 Valbonne, France \\ ${ }^{\perp}$ Laboratoire de Pharmacognosie, UMR CNRS 8076 BioCIS, LabEx LERMIT, Faculté de Pharmacie, Université Paris-Sud, 92290 \\ Châtenay-Malabry, France \\ "School of Chemistry, Marine Biodiscovery, National University of Ireland Galway, Galway, Ireland \\ ${ }^{\S}$ Departamento de Fisiología, Facultad de Veterinaria, Universidad de Santiago de Compostela, Lugo 27002, Spain
}

\begin{abstract}
Crambescidin 816 is a guanidine alkaloid produced by the sponge Crambe crambe with known antitumoral activity. While the information describing the effects of this alkaloid in central neurons is scarce, Cramb816 is known to block voltage dependent calcium channels being selective for L-type channels. Moreover, Cramb816 reduced neuronal viability through an unknown mechanism. Here, we aimed to describe the toxic activity of Cramb816 in cortical neurons. Since calcium influx is considered the main mechanism responsible for neuronal cell death, the effects of Cramb816 in the cytosolic calcium concentration of cortical neurons were studied. The alkaloid decreased neuronal

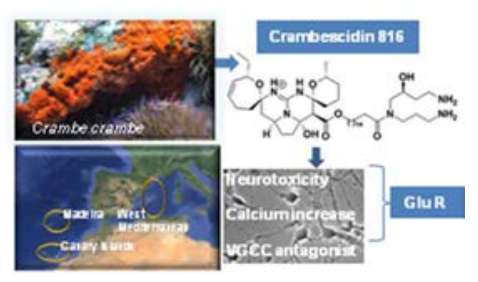
viability and induced a dose-dependent increase in cytosolic calcium that was also related to the presence of calcium in the extracellular media. The increase in calcium influx was age dependent, being higher in younger neurons. Moreover, this effect was prevented by glutamate receptor antagonists, which did not fully block the cytotoxic effect of Cramb816 after $24 \mathrm{~h}$ of treatment but completely prevented Cramb816 cytotoxicity after 10 min exposure. Therefore, the findings presented herein provide new insights into the cytotoxic effect of Cramb816 in cortical neurons.
\end{abstract}

KEYWORDS: Guanidine alkaloids, crambescidin 816, cortical neurons, cytosolic $\mathrm{Ca}^{2+}$, cytotoxicity, glutamate receptors

\section{INTRODUCTION}

Marine sponges are regarded as a good source of neuroactive natural products. ${ }^{1}$ The red encrusting marine sponge Crambe crambe, widely distributed in the Western Mediterranean Sea but also in the Macaronesian archipelagos produces several metabolites, including the guanidine alkaloids crambescins and crambescidins. $^{2-4}$ First, only a few studies assessed the biological activity of these compounds and their pharmaceutical potential, mainly due to the difficulties to obtain large quantities of pure compounds. ${ }^{5}$ Most of the reports considering the bioactivity of these molecules have revealed their cytotoxic activity in tumoral cells, and thus, these compounds are proposed as potential anticancer drugs. In this sense, some compounds from the crambescidin family such as crambescidin 800 and crambescidin 816 (Cramb816) are cytotoxic against tumor derived cell lines. ${ }^{6-9}$

The bioactivity of crambescidins in excitable cells has been less explored, and only a few reports consider the effects of these guanidine alkaloids in central neurons. Initially, an inhibitory activity of crambescidin 816 on voltage gated calcium channels (VGCCs) was reported in 1993. This crambescidin blocked $\mathrm{Ca}^{2+}$ channels with higher potency than the selective blocker of L-type VGCC nifedipine (NIF). ${ }^{2}$ In this sense, we recently confirmed the inhibitory activity of Cramb816 in primary cultures of cortical neurons demonstrating that Cav1 or L-type calcium channels are the main target for Cramb816 in this cellular model. ${ }^{10}$ In addition, this compound caused a small blockade of voltage gated sodium channels but did not affect voltage gated potassium channels as crambescins did, which indicated a clear structure-activity difference. ${ }^{10}$ In another report, Bondu et al. revealed that Cramb816 was cytotoxic to cortical neurons. ${ }^{4}$ However, so far there is no information regarding the mechanism by which this alkaloid is neurotoxic.

Typically, marine toxins induce cell death by increasing calcium influx into the cell. ${ }^{11,12}$ Massive calcium influx is regarded as one of the main mechanisms responsible for neuronal cell death. ${ }^{13,14}$ It has been traditionally accepted that the pharmacological blockade of the calcium overload prevents 
neuronal death, and thus VGCCs antagonists are considered good candidates for lowering neuronal damage. ${ }^{14}$ In this sense, L-type calcium channel antagonists have been proposed as promising tools for improving age-related working memory deficits. ${ }^{15}$ Since antagonists of voltage gated calcium channels have neuroprotective roles, ${ }^{16}$ the previously described finding that Cramb816 was toxic for cortical neurons, ${ }^{4}$ while acting as an antagonist of L-type calcium channel, ${ }^{2,10}$ was somehow surprising. Here, in order to gain insight into the possible mechanism of Cramb816 cytotoxicity in cortical neurons, several concentrations of Cramb816 were evaluated in neuronal viability and cytosolic calcium concentration. The results presented here indicate that Cramb816 did not elicit calcium influx at the concentration that blocked L-type calcium channels $(1 \mu \mathrm{M})$. However, at this concentration, it was slightly cytotoxic to cortical neurons. At higher concentrations, Cramb816 was neurotoxic and induced calcium influx in a concentration-dependent manner. The pharmacological profile of the calcium influx elicited by Cramb816 was characterized using the $N$-methyl-D-aspartate receptor (NMDA) selective antagonist D-(-)-2-amino-5-phosphonopentanoate (APV) and the $\alpha$-amino-3-hydroxy-5-methyl-4-isoxazolepropionic acid (AMPA) receptor selective antagonist 6-cyano-7-nitroquinoxaline-2,3-dione (CNQX). The calcium influx elicited by Cramb816 was partially blocked by APV and fully blocked by the simultaneous preincubation of cortical neurons with APV and CNQX, thus indicating that the Cramb816 induced calcium influx was mediated by both NMDA and AMPA glutamate receptor subtypes. In addition, these glutamate receptors antagonists decreased the neuronal death produced by Cramb816. Therefore, the results presented herein provide evidence that Cramb816 is neurotoxic to cortical neurons through a mechanism involving glutamate receptor activation and, in addition, the alkaloid produces an increase in cytoplasmic calcium concentration involving glutamate receptors.

\section{RESULTS AND DISCUSSION}

Effect of Cramb816 in Neuronal Viability. To study the cytotoxic effect of Cramb816 in cortical neurons, 4-6 DIV cells were exposed during $24 \mathrm{~h}$ to different concentrations of Cramb816 ranging from 0.01 to $10 \mu \mathrm{M}$. The chemical structure of Cramb816 is shown in Figure 1A. As shown in Figure 1B, Cramb816 lowered cellular viability in a dose-dependent manner. While at concentrations of $0.01 \mu \mathrm{M}$ and $0.1 \mu \mathrm{M}$
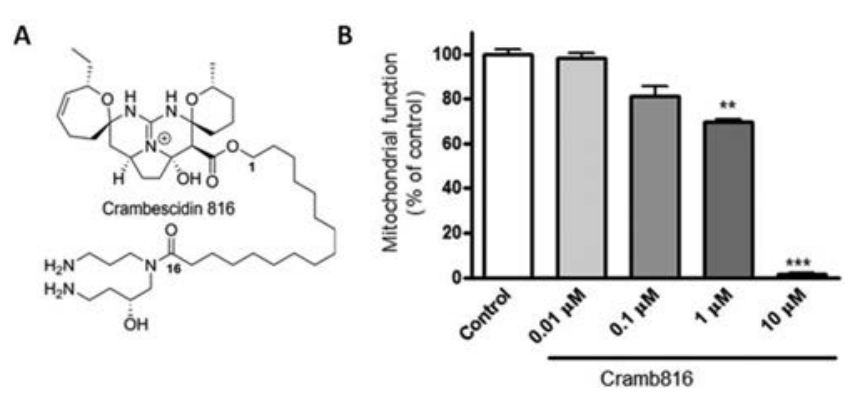

Figure 1. Effect of Cramb816 in neuronal viability. (A) Chemical structure of Cramb816. (B) Exposure of cortical neurons to Cramb816 for $24 \mathrm{~h}$ reduced cellular viability in a dose dependent manner Neuronal viability was determined by measuring mitochondrial function with the MTT method using three different experiments from three different cultures. $* * p<0.01 ; * * p<0.001$.
Cramb816 was not toxic, the compound at 1 and $10 \mu \mathrm{M}$ lowered cellular viability by $30.5 \% \pm 1.0 \%(n=3 ; p=0.002 ; t=$ 13.32; $\mathrm{df}=4)$ and $98.3 \% \pm 0.3 \%(n=3 ; p<0.0001 ; t=47.12$; $\mathrm{df}=4)$, respectively. The ${ }^{1} \mathrm{H}$ NMR spectrum of Cramb816 $(500 \mathrm{MHz})$ is shown in Supplementary Figure 1. Additionally, Supplementary Figure 2 shows the HPLC and HRMS data for Cramb816.

These results are in contrast with a previous report where Cramb816 produced almost complete cell death at $1 \mu \mathrm{M}$ decreasing cell viability by $86.3 \% \pm 6.8 \%$, ${ }^{4}$ whereas at the same concentration in the present study Cramb816 only lowered cellular viability by $30.5 \%$. One possible explanation for this difference could be that in the previous experimental conditions cortical neurons were cultured in medium containing high levels of potassium $(25 \mathrm{mM} \mathrm{KCl})$ while in our culture conditions the $\mathrm{KCl}$ concentration in the extracellular media was $5.3 \mathrm{mM}$. In order to clarify the difference between the toxicity of Cramb 816 among culture conditions, neurons were treated with $25 \mathrm{mM} \mathrm{KCl}$ in the absence and presence of $1 \mu \mathrm{M}$ Cramb816. As shown in Supplementary Figure 3, incubation with $25 \mathrm{mM} \mathrm{KCl}$ produced an almost complete cell death of cortical neurons reducing the cellular viability by $81.9 \% \pm 5.2 \%$ $(n=3 ; p<0.0019 ; t=5.267 ; \mathrm{df}=6)$. A similar result was obtained in those cells co-incubated with $25 \mathrm{mM} \mathrm{KCl}$ and 1 $\mu \mathrm{M}$ Cramb816 where neuronal viability decreased by $86.5 \% \pm$ $4.4 \%(n=3 ; p<0.001 ; t=5.614 ; \mathrm{df}=6)$.

High Concentrations of Cramb816 Increase the Cytosolic Calcium Concentration $\left[\mathrm{Ca}^{2+}\right]_{c}$ in Cortical Neurons. Since calcium influx is considered one of the main mechanisms involved in neuronal cell death, ${ }^{13,14}$ the effect of Cramb816 on the cytosolic calcium concentration in cortical neurons was analyzed. Inasmuch as the previous work on crambescidin cytotoxicity ${ }^{4}$ in cortical neurons was performed in cultures of 4-6 DIV, first, young neurons were exposed to Cramb816 concentrations ranging from 1 to $10 \mu \mathrm{M}$ in order to evaluate the effect of this compound on $\left[\mathrm{Ca}^{2+}\right]_{\mathrm{c}}$. Figure 2 shows the effect of bath application of Cramb816 at 1,5 , and $10 \mu \mathrm{M}$ on the cytosolic calcium concentration in cortical neurons. Since depletion of calcium ions from the endoplasmic reticulum (ER) or mithocondria has been suggested as an initial signal for intracellular calcium elevation and neuronal apoptosis, ${ }^{17,18}$ initially the effect of Cramb816 on $\left[\mathrm{Ca}^{2+}\right]_{\mathrm{c}}$ was evaluated using $\mathrm{Ca}^{2+}$-free media. As observed in Figure $2 \mathrm{~A}$, in the absence of $\mathrm{Ca}^{2+}$ in the extracellular medium, Cramb816 did not affect the $R_{340 / 380}$, thus indicating that intracellular $\mathrm{Ca}^{2+}$ stores were not affected by the guanidine alkaloid. However, when $1 \mathrm{mM} \mathrm{Ca}^{2+}$ was added to the bath solution, Cramb816 induced $\mathrm{Ca}^{2+}$ influx in a concentration dependent manner. The alkaloid at concentrations of 5 and $10 \mu \mathrm{M}$, but not at the lowest concentration evaluated $(1 \mu \mathrm{M})$, induced a rapid calcium influx in cortical neurons. Moreover, the calcium influx induced by 5 $\mu \mathrm{M}$ Cramb816 started about $100 \mathrm{~s}$ after the addition of the compound, while at $10 \mu \mathrm{M}$ the effect was immediate. Figure $2 \mathrm{~B}$ shows the medium $\left[\mathrm{Ca}^{2+}\right]_{c}$ measured $5 \mathrm{~min}$ after bath application of 5 and $10 \mu \mathrm{M}$ Cramb816 in calcium containing medium. In these conditions the, $R_{340 / 380}$ was significantly enhanced by $30.8 \% \pm 6.4 \%(n=3, p=0.088 ; t=4.779$; $\mathrm{df}=4)$ and $53 . \% 8 \pm 9.7 \%(p=0.005 ; t=5.518 ; \mathrm{df}=4)$ after addition of 5 or $10 \mu \mathrm{M}$ Cramb816, respectively, while at the lower concentration, $1 \mu \mathrm{M}$ Cramb816 enhanced $R_{340 / 380}$ only by $10.9 \% \pm 4.4 \%$, an effect that was not statistically significant $(n=$ 3; $p=0.11$ ). 
A

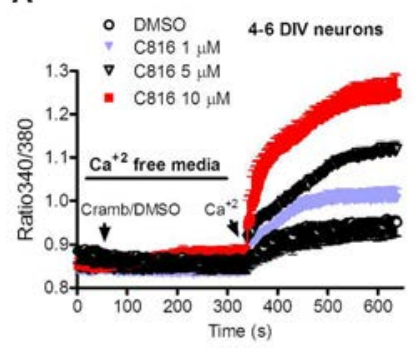

C

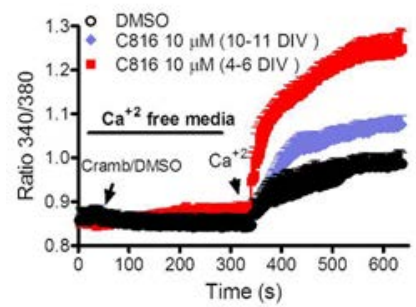

B

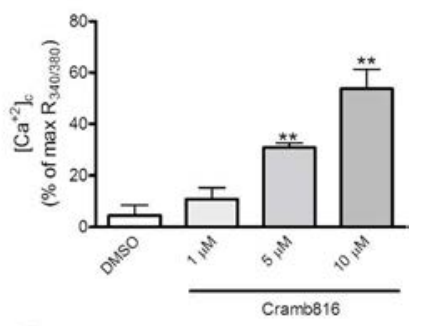

D

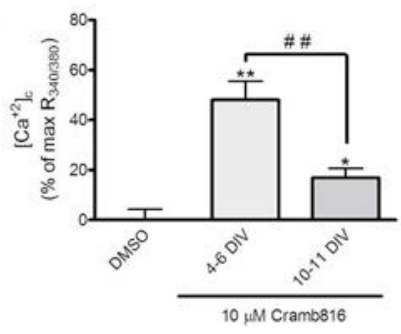

Figure 2. Effects of Cramb816 on cytosolic calcium concentration in cortical neurons. (A) In young neurons, Cramb816 did not affect $\left[\mathrm{Ca}^{2+}\right]_{\mathrm{c}}$ in a calcium-free media, but it produced a concentrationdependent rise in $\left[\mathrm{Ca}^{2+}\right]_{\mathrm{c}}$ after addition of calcium to the extracellular media. The arrow indicates solvent/drug and calcium addition to the bathing solution. (B) Pooled results for the increase in $\left[\mathrm{Ca}^{2+}\right]_{\mathrm{c}}$ produced by Cramb816 at the different concentrations after addition of calcium to the bathing media. (C) Effect of $10 \mu \mathrm{M}$ Cramb816 on $\left[\mathrm{Ca}^{2+}\right]_{\mathrm{c}}$ in young $(4-6 \mathrm{DIV})$ and mature $(10-12 \mathrm{DIV})$ cortical neurons. Arrows indicate drug/DMSO and calcium addition to the bathing solution. (D) Pooled results for the shift in $\left[\mathrm{Ca}^{2+}\right]_{\mathrm{c}}$ produced by $10 \mu \mathrm{M}$ Cramb816 in the two groups. $* p<0.05$; $* *<0.01$ versus control; \#\#p < 0.01 between young and mature neurons. Results were obtained from three different experiments and cultures.

Several reports indicate calcium homeostasis changes during neuronal development. ${ }^{19}$ In this sense, spontaneous $\mathrm{Ca}^{2+}$ activity during early neocortical development depends mainly on gap junctions and voltage dependent $\mathrm{Ca}^{2+}$ channels, whereas later in development neurotransmitters and synapses exert an influence. $^{20}$ In the cerebral cortex, synchronized rhythmic activity also develops spontaneously in neuronal networks formed by embryonic neurons in cell culture, and this is accompanied by changes in $\mathrm{Ca}^{2+}$ transients. ${ }^{21}$ Thus, we investigated whether the calcium influx pattern exerted by Cramb816 was dependent on the time that neurons were maintained in culture. Therefore, in the next set of experiments, the calcium influx elicited by Cramb816 in immature (4-6 DIV) and mature cortical neurons (10-11 DIV) was compared. As observed in Figure $2 \mathrm{C}$, in a $\mathrm{Ca}^{2+}$ free media, $10 \mu \mathrm{M}$ Cramb816 did not affect the $R_{340 / 380}$ in either of the two age groups; however, in the presence of $1 \mathrm{mM} \mathrm{Ca}^{2+}$ in the bath solution, $10 \mu \mathrm{M}$ Cramb816 induced calcium influx in both

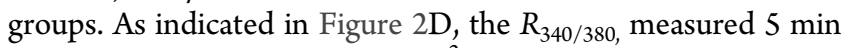
after the addition of $1 \mathrm{mM} \mathrm{Ca}{ }^{2+}$ to the bath solution, was enhanced by $48.05 \% \pm 8.1 \%(n=3 ; p=0.002 ; t=5.901$; $\mathrm{df}=$ $5)$ in $4-6$ DIV cortical neurons and only by $16.9 \% \pm 5.7 \%(n=$ 3 ; $p=0.003 ; t=2.929 ; \mathrm{df}=6)$ in older neurons. The difference between both groups was statistically significant $(p<0.0 ; t=$ 4.060; $\mathrm{df}=5$ ) thus indicating that 4-6 DIV neurons were more susceptible than 10-11 DIV neurons to Cramb816.

Finally, we also evaluated the effect of the compound when it was added directly in calcium containing media (Supplementary Figure 4) using young neurons. In this condition, Cramb816 also elicited a concentration-dependent increase in calcium (Supplementary Figure 4A), which was of a similar magnitude to that observed previously. In calcium containing media, the $\left[\mathrm{Ca}^{2+}\right]_{c}$ was not modified by bath application of Cramb816 at $1 \mu \mathrm{M}$; however, it increased by $32.2 \% \pm 10.4 \%(n$ $=3 ; p=0.0367 ; t=3.085 ; \mathrm{df}=4)$ and $59.4 \% \pm 15.7 \%(n=3 ; p$ $=0.0195 ; t=3.778 ; \mathrm{df}=4)$ after addition of Cramb816 at 5 and $10 \mu \mathrm{M}$, respectively (Supplementary Figure 4B).

$\mathrm{Ca}^{2+}$ ions may gain access to the neuronal cytoplasm via ion channels or $\mathrm{Ca}^{2+}$ transport systems or through the release of $\mathrm{Ca}^{2+}$ ions from intracellular stores. Since the latter option was discarded because Cramb816 did not affect cortical neurons in the absence of $\mathrm{Ca}^{2+}$ in the extracellular media, the following experiments were performed in media containing $1 \mathrm{mM} \mathrm{Ca}^{2+}$. In the next set of experiments, we aimed to analyze the route underlying the Cramb816-dependent $\mathrm{Ca}^{2+}$ influx in cortical neurons. A concentration of $10 \mu \mathrm{M}$ Cramb816 was chosen to further elucidate the target for Cramb816 induced calcium influx by using different pharmacological approaches.

The Voltage-Gated Calcium Channel Blocker Nifedipine Did Not Impede the Cytosolic Calcium Increase Elicited by Cramb816. In neurons, the entry of calcium is regulated mainly by voltage-gated channels and by receptor operated channels activated by glutamate. Despite the fact that Cramb816 is an antagonist of voltage gated calcium channels, this activity was observed at $1 \mu \mathrm{M},{ }^{10}$ a concentration that in our cellular model and conditions did not induce calcium influx. To investigate the molecular basis of Cramb816 induced $\mathrm{Ca}^{2+}$ increase, the effect of $10 \mu \mathrm{M}$ Cramb816 in the presence of the L-type voltage gated calcium channel blocker nifedipine (NIF) was first analyzed. For this purpose, NIF was added $30 \mathrm{~min}$ prior to the administration of $10 \mu \mathrm{M}$ Cramb816. This pharmacological manipulation did not impede the calcium increase elicited by Cramb816 (Figure 3A). As indicated in Figure $3 \mathrm{~B}$, the $R_{340 / 380}$ was significantly enhanced after the addition of $10 \mu \mathrm{M}$ Cramb816 by $45.9 \% \pm 12.9 \%(n=3, p=$ $0.03 ; t=3.170 ; \mathrm{df}=4)$. A similar result was obtained when 10 $\mu \mathrm{M}$ Cramb816 was added after the incubation for $30 \mathrm{~min}$ with $10 \mu \mathrm{M}$ NIF. In this case, the $R_{340 / 380}$ was increased by $45.9 \% \pm$
A

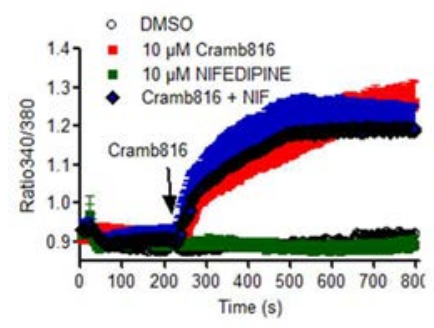

B

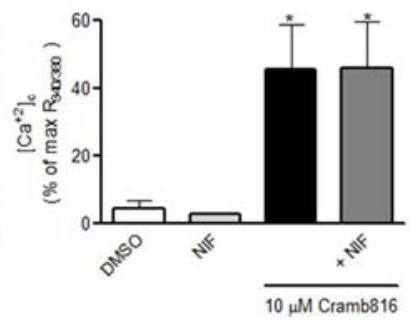

Figure 3. The cytosolic calcium increase elicited by Cram 816 was not dependent on voltage-gated calcium channels. (A) Incubation of cortical neurons with $10 \mu \mathrm{M}$ nifedipine (NIF) $30 \mathrm{~min}$ before bath application of Cramb816 did not modify the calcium influx elicited by Cramb816 at $10 \mu \mathrm{M}$. (B) Pooled results for the shift in $\left[\mathrm{Ca}^{2+}\right]_{\mathrm{c}}$ produced by $10 \mu \mathrm{M}$ Cramb816 in the absence and presence of the voltage-gated calcium channel blocker nifedipine. ${ }^{*} p<0.05$ versus the respective control. Results were obtained from three different experiments and cultures. 
$13.6 \%(n=3 ; p=0.03 ; t=3.161 ; \mathrm{df}=4)$ thus indicating that the calcium influx elicited by Cramb816 in cortical neurons was not through L-type voltage gated calcium channels.

Glutamate Receptors Antagonists Impeded the Calcium Influx Induced by Cramb816. In order to study whether NMDARs were involved in the Cramb816-induced calcium influx, NMDARs were blocked by $100 \mu \mathrm{M}$ APV added to the bath solution $30 \mathrm{~min}$ before Cramb816. In this conditions, the Cramb816 dependent $\mathrm{Ca}^{2+}$ influx was partially reduced by the presence of APV (Figure 4A). As indicated in
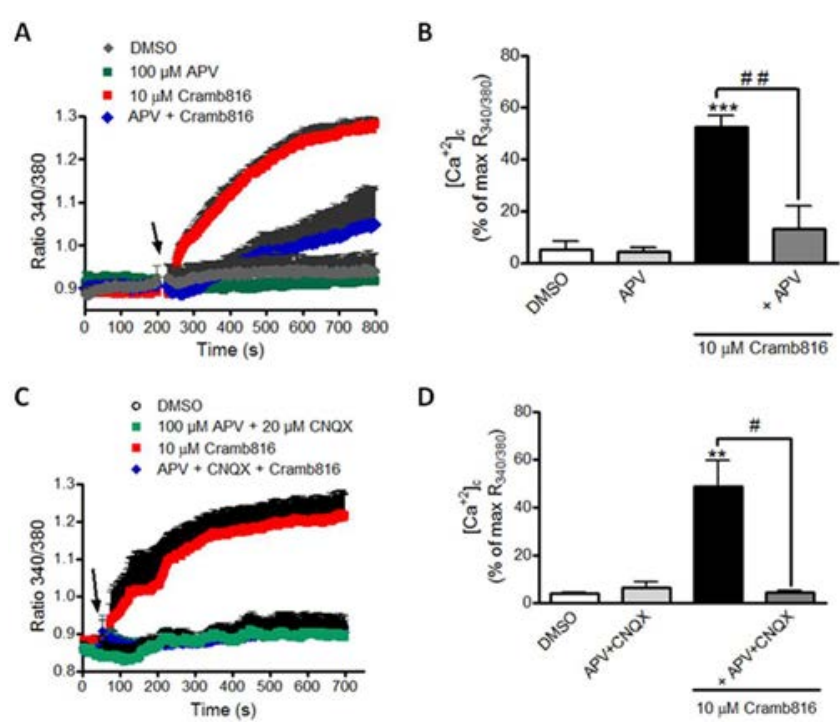

D

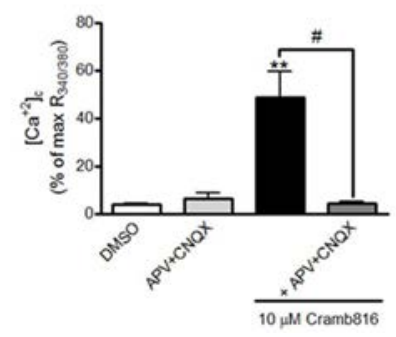

indicated in Figure 4D, the $R_{340 / 380}$ was significantly enhanced after the addition of $10 \mu \mathrm{M}$ Cramb 816 by $48.7 \% \pm 10.8 \%(n=$ $3 ; p=0.01 ; t=4.138 ; \mathrm{df}=4)$. However, when $10 \mu \mathrm{M}$ Cramb816 was added after the incubation for $30 \mathrm{~min}$ with the glutamate receptor antagonists, APV and CNQX, the increase in the $R_{340 / 380}$ elicited by $10 \mu \mathrm{M}$ Cramb816 was only $1.7 \% \pm$ $2.5 \%$. Thus, the complete blockade of glutamate receptors by the combination of APV and CNQX impeded the rise in cytosolic calcium elicited by the guanidine alkaloid. These results indicate that the calcium increase elicited by Cramb816 in cortical neurons involves both AMPA and NMDA receptors.

Glutamate Receptors Antagonists Improved Cramb816-Induced Cytotoxicity in Cortical Neurons. In order to study whether glutamate receptors were also involved in the cytotoxic effects of Cramb816, cortical neurons were coincubated with the glutamate receptor antagonists APV and CNQX prior to the addition of Cramb816 to the extracellular media. As observed in Figure 5A, when neurons were exposed to Cramb816 for $24 \mathrm{~h}$ in a media containing APV and CNQX, the effect of the alkaloid was about $10 \%$ or $20 \%$ lower than the cytotoxicity in the absence of glutamate receptor antagonists.
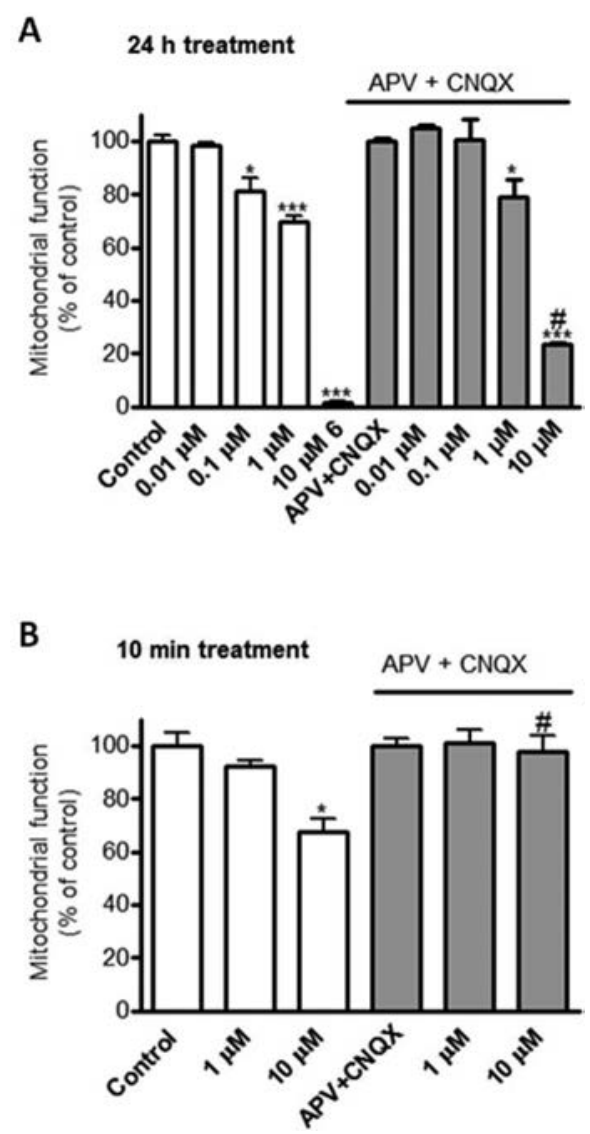

Figure 5. The cytotoxic effect of Cramb816 in cortical neurons was mediated by glutamate receptors. (A) Exposure $(24 \mathrm{~h})$ of cortical neurons to Cramb816 reduced cellular viability in a dose dependent manner (white bars) and this effect was ameliorated by the simultaneous blockade of NMDA and AMPA receptors in the presence of APV and CNQX (gray bars). (B) Exposure (10 min) of cortical neurons to 1 and $10 \mu \mathrm{M}$ Cramb816 reduced cellular viability only at the highest alkaloid concentration (white bars), and this effect was completely reverted by the simultaneous blockade of NMDA and AMPA receptors in the presence of APV and CNQX. $*_{p}<0.05$, ***p $<0.005$ versus control; $\# p<0.05$ versus Cramb816. 
This result indicated that the cytotoxic effect elicited by Cramb816 at $24 \mathrm{~h}$ was mitigated but not impeded by the pharmacological blockade of glutamate receptors. As shown in Figure 5A, in the absence of glutamate receptor antagonists Cramb816 elicited a cytotoxic effect at $0.1 \mu \mathrm{M}$, while in the presence of APV + CNQX, this alkaloid concentration was not toxic to cortical neurons. The effect of glutamate receptor antagonist was most profound at the higher toxin concentrations. Thus, at $10 \mu \mathrm{M}$ Cramb816, the mitochondrial function was $1.7 \% \pm 0.2 \%$ of control, indicating an almost complete cell death, while when the cells where co-incubated with glutamate receptor antagonists and $10 \mu \mathrm{M}$ Cramb816 the mitochondrial function was $23.7 \% \pm 0.2 \%(p<0.0001 ; t=53.49$; df $=4)$. Since the duration of the experiments assessing the activity of Cramb816 on intracellular calcium concentration was about 5$10 \mathrm{~min}$, the effect of Cramb816 in neuronal viability was studied after exposing cortical neurons to the alkaloid either alone or in the presence of glutamate receptor antagonists during $10 \mathrm{~min}$ (Figure 5B). In these conditions, $10 \mu \mathrm{M}$ Cramb816 reduced cellular viability by $32.37 \% \pm 6.519 \%(n=$ 3; $p=0.0077 ; t=4.966$; $\mathrm{df}=4)$, whereas $1 \mu \mathrm{M}$ Cramb816 did not significantly affect neuronal viability. In contrast, in those experiments where neurons were preincubated with APV and CNQX, the alkaloid did not significantly modified cellular viability at the highest concentration. A significant difference in the cytotoxicity of Cramb816 in the absence and presence of glutamate receptor antagonists was found $(n=3 ; p=0.0145 ; t$ $=4.127 ; \mathrm{df}=4)$, again indicating that the cytotoxic effect of Cramb816 in cortical neurons involved glutamate receptors.

Cramb816 Increases the Amplitude of mEPSCs in Cortical Neurons. Finally, the effect of the toxin on miniature excitatory synaptic events (mEPSCs), which are generally assumed to report synaptic function at the level of a single terminal, representing the postsynaptic response to release of individual vesicles of glutamate, ${ }^{22,23}$ was also evaluated. mEPSCs were pharmacologically isolated as described in the Methods section. These mEPSCs in cortical neurons were glutamatergic as previously described in this cellular model by their complete pharmacological blockade by the combination of APV and CNQX. ${ }^{24}$ A representative recording of mEPSC before and after addition of $10 \mu \mathrm{M}$ Cramb816 is shown in Figure 6A. Amplified recordings from the same neuron, before and after addition of the toxin, are shown in Figure 6B. All together these experiments indicate that bath application of Cramb816 increased the amplitude and frequency of mEPSCs.

Members of the crambescidin family have been reported with antifungicidal, antibacterial, antiviral, and also antitumoral activities in several preparations. ${ }^{6-9,25-27}$ However, less attention has been paid to the activity of these compounds in the central nervous system. In this sense, the major finding for the effects of a member of the crambescidin family in a neuronal model was the selectivity of Cramb816 for L-type sensitive calcium channels in cortical neurons. ${ }^{10}$ Moreover, it was also described that this compound was cytotoxic in these neurons. ${ }^{4}$ The main result of this study was that Cramb816 produced calcium influx in a dose dependent manner, and this effect was blocked by glutamate receptor antagonists. Moreover, at $10 \mu \mathrm{M}$, the alkaloid induced neuronal death at $24 \mathrm{~h}$, and this effect was ameliorated but not fully avoided by glutamate receptor antagonists. In addition, exposure of cortical neurons to high concentrations of the compound for $10 \mathrm{~min}$ also caused toxicity in cortical neurons, but in this case, the cytotoxic effect was fully blocked by coadministration of
A

mEPSCs (presence of TTX and BIC)

B
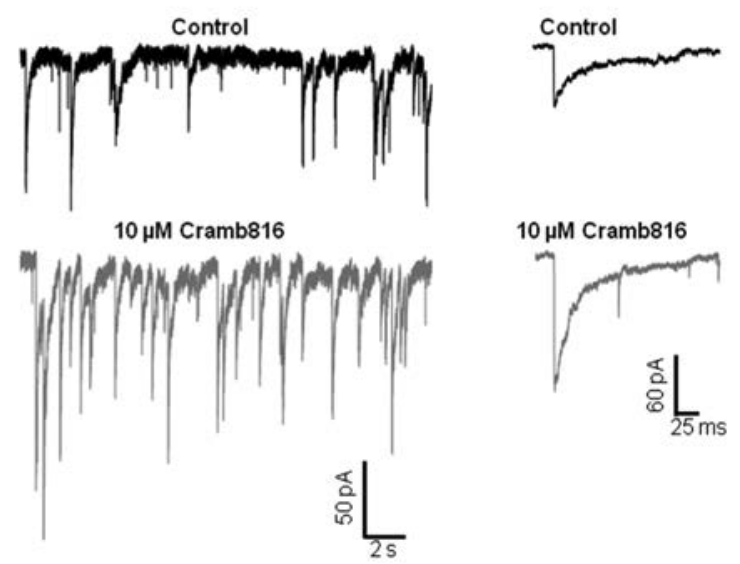

Figure 6. Cramb816 increased the amplitude and frequency of mEPSCs. (A) Representative traces of mEPSCs recorded in control conditions (upper panel) and in neurons acutely treated with $10 \mu \mathrm{M}$ Cramb816 (lower panel). (B) Detailed image of a single mEPSC in control conditions (upper panel) and after $10 \mu \mathrm{M}$ Cramb816 addition (lower panel).

NMDA/AMPA receptor antagonists. It is noteworthy that at 1 $\mu \mathrm{M}$, a concentration known to produce blockade of L-type voltage gated calcium channels, ${ }^{10}$ Cramb816 did not acutely produce calcium influx or cellular death but it was slightly cytotoxic to cortical neurons after $24 \mathrm{~h}$ treatment.

Previous works had shown that $1 \mu \mathrm{M}$ Cramb816 did not affect the cellular viability of the tumor cell line OU-31 after a $24 \mathrm{~h}$ exposure. ${ }^{9}$ However, in other tumor cell lines, this compound reduced cellular viability in a concentrationdependent manner and by percentages ranging between $17 \%$ and 39\%. ${ }^{9}$ Recently, it was also demonstrated that Cramb816 reduced the viability of a wide range of tumor cell lines with $\mathrm{IC}_{50}$ of $0.12 \mu \mathrm{M}$ after $72 \mathrm{~h}$ of treatment. Initial viability assays of cortical neurons treated for $24 \mathrm{~h}$ with different concentrations of Cramb816 showed that this compound was highly neurotoxic at a concentration of $1 \mu \mathrm{M}$ causing almost complete cell death at this concentration, ${ }^{4}$ an unexpected fact since at this concentration the alkaloid has been shown to act as a blocker of voltage-gated calcium channels in the same in vitro model. In this work, we reevaluated the neurotoxic effect of Cramb816 in cortical neurons cultured in media containing a physiological concentration of potassium instead of a high potassium concentration, and the results presented herein indicated that exposure of cortical neurons to $1 \mu \mathrm{M}$ Cramb816 reduced cell viability only by $30 \%$ and caused complete cell death at concentrations 10 times higher, an effect similar to that recently described in tumoral cell lines. ${ }^{7}$ We suggest that the differences observed between our results and the previous report describing the cytotoxic effect of Cramb816 in cortical neurons can be assigned to the differences between experimental conditions. The higher extracellular potassium concentration used in our previous work $^{4}$ was probably exacerbating the toxicity of Cramb816 and could interfere in previous results where Cramb816 produced complete cell death at $1 \mu \mathrm{M}$ and was cytotoxic at lower concentrations after a $24 \mathrm{~h}$ exposure of cortical neurons to the alkaloid. In this sense, we here demonstrated that a medium containing $25 \mathrm{mM} \mathrm{KCl}$ is not an adequate media to perform a cytotoxicity assay in cortical 
neurons. In fact, whereas this condition is necessary in primary cultures of rat cerebellar granule neurons, ${ }^{28}$ it has been reported to be neurotoxic in cortical neurons ${ }^{29}$ and to impede neuronal activity due to the excessive membrane depolarization in cerebral cortex. $^{30}$

On the other hand, one possible mechanism responsible for the neuronal cell death elicited by Cram 816 could be the excessive accumulation of calcium, ${ }^{13,14,31,32}$ since intracellular calcium levels are critical to regulate apoptosis. ${ }^{33-35}$ Potentially neurotoxic cytoplasmic calcium concentrations can be produced by the access of $\mathrm{Ca}^{2+}$ ions to the neuronal cytoplasm via ion channels (voltage gated calcium channels), $\mathrm{Ca}^{2+}$ transport systems, ${ }^{36}$ release of $\mathrm{Ca}^{2+}$ ions from internal stores, physical damage to mitochondria and the endoplasmic reticulum, or a malfunction of receptors and channels present in their membranes. ${ }^{37}$ Here, Cramb816 did not affect internal organelles as evidenced by the lack of effect in a calcium free media. Since other marine compounds have been broadly reported to cause cellular death by inducing calcium influx from the extracellular media, ${ }^{11,12,38}$ we also explored this possibility. In this case, Cramb816 induced calcium influx from the extracellular media at 5 and $10 \mu \mathrm{M}$. However, it did not promote calcium influx at $1 \mu \mathrm{M}$, a concentration that was not cytotoxic to cortical neurons when exposed to the compound for $10 \mathrm{~min}$ and that is known to produce blockade of L-type calcium channels. ${ }^{10}$ This latter result is logical since VGCC antagonists are considered as good candidates for lowering neuronal damage. ${ }^{14}$ However, at $24 \mathrm{~h}, 1 \mu \mathrm{M}$ Cramb816 was slightly cytotoxic to cortical neurons similar to the effect produced by other calcium channel antagonists such as NIF, which also has been described to be cytotoxic in cerebral cortical cultures after 2 days of treatment. ${ }^{39}$ L-type calcium channel antagonists have been proposed as pharmacological tools for improving age-related working memory deficits. ${ }^{15}$ However, it might seem controversial that a ten times higher concentration of this L-type channel blocker, in theory neuroprotective, led to massive calcium influx and was toxic to neurons. Nevertheless, other compounds have been shown to play neuroprotective roles at a 10 times lower concentration than the concentration needed to be neurotoxic. ${ }^{40}$ In fact, the chemical structure of crambescidins consist of pentacyclic guanidines linked by a linear $\omega$-hydroxy fatty acid to a spermidine or hydroxyspermidine unit, ${ }^{41}$ and polyamines have been previously shown to have biphasic effects on neuronal calcium channels. ${ }^{42}$

In neurons, calcium ions from the extracellular media can enter into the cell through several mechanisms including the activation of glutamate receptors or of a range of channels and transporters including L-type calcium channels. ${ }^{37}$ In this sense, massive $\mathrm{Ca}^{2+}$ influx can be mediated through glutamate receptors when excessive glutamate release induces excitotoxicity. ${ }^{43}$ We first hypothesized that Cramb816 at $10 \mu \mathrm{M}$ could induce calcium influx via VGCC at a concentration ten times higher than that needed to exert an antagonist effect against these calcium channels. In fact, there are many molecules in nature that produced concentration-dependent opposite effects. ${ }^{44,45}$ It must be pointed out that although it is generally assumed that voltage gated calcium channels do not carry toxic amounts of $\mathrm{Ca}^{2+}$ into neurons, it has been recently described that VGCC may take part in neurodegeneration by inducing calcium loads into neurons. ${ }^{46}$ However, in our conditions, the L-type calcium channel blocker NIF did not impede the calcium influx elicited by Cramb816, therefore indicating that the increase in calcium elicited by Cramb816 was not mediated by VGCC. Furthermore, the fact that the calcium influx was higher in younger than in older cortical neurons was also in contradiction with a calcium influx through L-type calcium channels since it is well-known that L-type calcium currents are larger in older neurons ${ }^{47}$ which are more vulnerable to death in an L-type channel dependent manner. ${ }^{36}$ Second, we studied the possibility that the calcium influx induced by the guanidine alkaloid was mediated by glutamate receptors. Glutamate, the major excitatory neurotransmitter in the central nervous system, participates in a number of physiological and pathological processes. Under many pathological conditions, excessive glutamate release induces excitotoxicity, a condition that is characterized by massive $\mathrm{Ca}^{2+}$ influx mainly through NMDARs. ${ }^{43}$ It is known that AMPA and NMDA glutamate receptors differ in several functional properties including the calcium permeability. Whereas NMDA receptors are typically permeable to $\mathrm{Na}^{+}$and $\mathrm{Ca}^{2+}$, AMPA receptors are permeable to $\mathrm{K}^{+}$and $\mathrm{Na}^{+}$but less permeable to $\mathrm{Ca}^{2+} \cdot{ }^{27}$ However, the presence of calcium permeable AMPA receptors has been suggested as an alternative route for neuronal vulnerability to excitotoxicity in cortical neurons. ${ }^{48}$ Therefore, it was expected that the blockade of NMDA receptors almost completely impeded the increase in cytosolic calcium elicited by Cramb816. Interestingly, when both AMPA and NMDA receptors were simultaneously blocked, Cramb816 did not produce any calcium influx in cortical neurons, thus indicating that the calcium influx produced by this guanidine alkaloid was mediated by both AMPA and NMDA receptors. Furthermore, the fact that Cramb816 enhanced the frequency of mEPSCs, indicating that the alkaloid increased the release of glutamatergic vesicles, accounts for another piece of evidence indicating that Cramb816 affects glutamate receptors at high concentrations. In this context, it must be noted that the release of neurotransmitter vesicles is regulated by intracellular calcium levels. ${ }^{49}$ Moreover, glutamate receptor antagonists ameliorated the toxicity elicited by Cramb816 after $24 \mathrm{~h}$ and fully reverted the acute toxicity of the compound.

Taken together, the results presented in this work suggest that the cytotoxic effect of Cramb816 in cortical neurons is related to an increase in the cytosolic calcium concentration elicited by the toxin, which was shown to be mediated by glutamate receptor activation.

\section{METHODS}

Primary Cultures of Cortical Neurons. Swiss mice were used to obtain primary cultures of cortical neurons. All protocols were approved by the University of Santiago de Compostela Institutional animal care and use committee. Primary cortical neurons were obtained from embryonic day 16-18 Swiss mice as previously described. $^{24,50}$ Briefly, cerebral cortices were removed and dissociated by mild trypsinization, followed by mechanical trituration in a DNase solution $(0.004 \% \mathrm{w} / \mathrm{v})$ containing a soybean trypsin inhibitor $(0.05 \%$ $\mathrm{w} / \mathrm{v})$. The cells were suspended in Neurobasal medium supplemented with $1 \%$ B-27 supplement (Gibco), $5 \mathrm{~mm} \mathrm{L-glutamine,} \mathrm{and} 1 \%$ penicillin/streptomycin. The cell suspension was seeded in multiwell plates precoated with poly(D-lysine), and the cell culture was kept in a $95 \%$ air, $5 \% \mathrm{CO}_{2}$ atmosphere at $37{ }^{\circ} \mathrm{C}$. Culture medium was replaced every 3-4 days.

Determination of Cellular Viability. Cell viability was assessed by the MTT (3-[4,5-dimethylthiazol-2-yl]-2,5-diphenyltetrazolium bromide) test, as previously described. ${ }^{11}$ This assay, which measures mitochondrial function, was performed in cultures grown in 96 well plates and exposed to different concentrations of Cramb816 added to the culture medium during either $24 \mathrm{~h}$ or $10 \mathrm{~min}$. Cultures were 
maintained in the presence of the toxins at $37{ }^{\circ} \mathrm{C}$ in a humidified $5 \%$ $\mathrm{CO}_{2} / 95 \%$ air atmosphere. Saponin was used as cellular death control, and its absorbance was subtracted from the other data. After the exposure time, cells were rinsed and incubated for $60 \mathrm{~min}$ with a solution of MTT ( $500 \mu \mathrm{g} \mathrm{mL}^{-1}$ ) dissolved in Locke's buffer containing in $\mathrm{mM} 154 \mathrm{NaCl}, 5.6 \mathrm{KCl}, 1.3 \mathrm{CaCl}_{2}, 1 \mathrm{MgCl}_{2}, 10 \mathrm{HEPES}$, and 5.6 glucose ( $\mathrm{pH}$ 7.4). After excess MTT was washed off, cells were disaggregated with $5 \%$ sodium dodecyl sulfate, and the absorbance of the colored formazan salt, as an indicator of the mitochondrial function of viable cells, was measured at $595 \mathrm{~nm}$ in a spectrophotometer plate reader.

Determination of the Cytosolic Calcium Concentration $\left(\left[\mathrm{Ca}^{2+}\right]_{\mathrm{c}}\right)$. Cell cultures of $4-6$ days in vitro (DIV) or $10-12$ DIV seeded onto $18 \mathrm{~mm}$ glass coverslips were washed twice with cold physiological saline solution supplemented with $0.1 \%$ bovine serum albumin (BSA). Saline solution was composed (in $\mathrm{mM}$ ) of $119 \mathrm{NaCl}$, $5.9 \mathrm{KCl}, 1 \mathrm{CaCl}_{2}, 1.2 \mathrm{MgSO}_{4}, 1.2 \mathrm{NaH}_{2} \mathrm{PO}_{4}, 22.8 \mathrm{NaHCO}_{3}$, and $0.1 \%$ glucose, ( $\mathrm{pH} 7.4$ adjusted with $\mathrm{CO}_{2}$ prior to use). Cortical neurons were loaded with the calcium sensitive dye Fura-2 AM $(0.5 \mu \mathrm{M})$ for 8 min at $37{ }^{\circ} \mathrm{C}$ in Locke's buffer containing $0.1 \%$ bovine serum albumin (BSA). After incubation, the loaded cells were washed three times with cold Locke's buffer. The glass coverslips were inserted into a thermostated chamber at $37{ }^{\circ} \mathrm{C}$ (Life Science Resources), and cells were viewed with a Nikon Diaphot 200 microscope, equipped with epifluorescence optics (Nikon 40X-immersion UV-Fluor objective). Addition of drugs was made by aspiration and addition of fresh bathing solution. The cytosolic calcium ratio was obtained from the images collected by fluorescence equipment (Lambda-DG4, Sutter Instrument Company, Novato, CA, USA). The light source was a xenon arc bulb, and the different wavelengths used were chosen with filters. The ratio of intensities of emitted light $(505 \mathrm{~nm})$ corresponding to excitation wavelengths of 340 and $380 \mathrm{~nm}\left(R_{340 / 380}\right)$ was taken as a measure of $\left[\mathrm{Ca}^{2+}\right]_{\mathrm{c}}$.

The experiments were performed in triplicate. In those experiments requiring L-type calcium channel blockade or glutamate receptor blockade, neurons were preincubated for $30 \mathrm{~min}$ with their respective antagonists. $^{51}$

Electrophysiology. Whole cell patch-clamp recordings, achieved by gentle mechanical suction of the membrane patch, were performed on cortical neurons, between 10 and 11 days in culture, at room temperature $\left(22-25{ }^{\circ} \mathrm{C}\right)$. A computer-controlled current and voltage clamp amplifier (Multiclamp 700B, Molecular Devices) was used. Signals were recorded and analyzed using a Pentium computer equipped with Digidata 1440 data acquisition system and pClamp10 software (Molecular Devices, Sunnyvale, CA). pClamp10 was used to generate current and voltage-clamp commands and to record the resulting data. Signals were filtered at $10 \mathrm{kHz}$ and digitized at $20 \mu \mathrm{s}$ intervals. Culture medium was exchanged with several washes of recording solution immediately prior to the experiment. After establishing the whole-cell configuration, neurons were allowed to stabilize for at least $5 \mathrm{~min}$ before experiments were initiated to ensure adequate equilibration between the internal pipet solution and the cell interior. Recording electrodes were fabricated from borosilicate glass microcapillaries (outer diameter, $1.5 \mathrm{~mm}$ ), and the tip resistance was 5-10 M . Only recordings with stable access resistance and holding current for at least $3 \mathrm{~min}$ were included in the analysis. The external solution in all the experiments contained (in $\mathrm{mM}$ ) $119 \mathrm{NaCl}, 5.9 \mathrm{KCl}$, $1 \mathrm{CaCl}_{2}, 1.2 \mathrm{MgSO}_{4}, 1.2 \mathrm{NaH}_{2} \mathrm{PO}_{4}, 22.8 \mathrm{NaHCO}_{3}$, and $0.1 \%$ glucose $\left(\mathrm{pH} 7.4\right.$ adjusted with $\mathrm{CO}_{2}$ prior to use), while intracellular pipet solutions contained (in $\mathrm{mM}$ ) $150 \mathrm{KCl}, 2 \mathrm{MgCl}_{2}, 5$ HEPES, 1.1 EGTA, and $2 \mathrm{Na}_{2} \mathrm{ATP}$ ( $\mathrm{pH}$ 7.2). Data were rejected if the initial resting potential was more depolarized than $-50 \mathrm{mV}$. Miniature synaptic events were recorded in voltage-clamp mode at a holding potential of $-80 \mathrm{mV}$. Miniature excitatory postsynaptic currents were recorded in the presence of the $\mathrm{GABA}_{\mathrm{A}}$ receptor antagonist, bicuculline (BIC) 20 $\mu \mathrm{M}$, and the VGSC blocker tetrodotoxin (TTX) at $0.5 \mu \mathrm{M}$ to block action potentials. Miniature excitatory postsynaptic currents (mEPSCs) were detected using an automatic template detection program (pCLAMP, Molecular Devices) and verified manually.
mEPSCs were confirmed by their complete inhibition in the presence of $20 \mu \mathrm{M}$ CNQX and $100 \mu \mathrm{M}$ APV as previously described. ${ }^{24}$

Toxins and Drugs Used. Cramb816 was extracted and isolated from the Mediterranean sponge Crambe crambe. ${ }^{4}$ Nifedipine (NIF) and $\mathrm{D}(-)$-2-amino-5-phosphonopentanoic acid (APV) were purchased from Sigma-Aldrich, and 6-cyano-7-nitroquinoxaline-2,3-dione (CNQX) was from Tocris. The final concentration of NIF or Cramb816 (solvent DMSO) was less than $0.01 \%$. APV and CNQX were dissolved in $\mathrm{H}_{2} \mathrm{O}$.

Statistical Analysis. All data are expressed as means \pm SEM of $n$ determinations. Statistical comparison was by Student's $t$ test. Values of $p-<0.05$ were considered statistically significant.

${ }^{1} \mathrm{H}$ NMR spectrum of Cramb816, HPLC and HRMS of Cramb816, effect of Cramb816 on neuronal viability in a medium containing $25 \mathrm{mM} \mathrm{KCl}$, and effect of Cramb816 on the cytosolic calcium concentration in a calcium containing media (PDF)

\section{AUTHOR INFORMATION}

\section{Corresponding Authors}

*Tel/Fax: 34-982822233. E-mail: luis.botana@.usc.es.

*Tel/Fax: 34-982822233. E-mail: mdelcarmen.vale@usc.es.

\section{ORCID $\odot$}

Olivier P. Thomas: 0000-0002-5708-1409

Carmen Vale: 0000-0002-9842-6223

\section{Author Contributions}

S.B.L.S. and O.P.T. performed the chemical purification and identification of Cramb816 and revised the manuscript. A.A., C.V., L.M.B., and M.R.V. developed the idea, designed experiments for the study, and wrote the manuscript with the help of A.G.M., A.B.J., and V.M. A.G.M., A.B.J., and V.M. performed the experiments, analyzed the data, and prepared the figures. All authors participated in discussions and proofreading of the manuscript.

\section{Notes}

The authors declare no competing financial interest.

\section{ACKNOWLEDGMENTS}

The research leading to these results has received funding from the following FEDER cofunded-grants. From CDTI and Technological Funds, supported by Ministerio de Economía, Industria y Competitividad, AGL2014-58210-R, AGL201678728-R (AEI/FEDER, UE), ISCIII/PI16/01830 and RTC2016-5507-2. From CDTI under ISIP Programme, Spain, IDI20130304 APTAFOOD and ITC-20161072. From the European Union's Seventh Framework Programme managed by REA-Research Executive Agency (FP7/2007-2013) under grant agreement 312184 PHARMASEA. The scholarship of S. Silva was funded by CAPES Foundation, Brazil (BEX 1018413-9).

\section{ABREVIATIONS}

Cramb816, crambescidin 816; NIF, nifedipine; VGCCs, voltage-gated calcium channels; CrambC, crambescin $\mathrm{C} 1$; NMDA, N-methyl-D-aspartate receptor; APV, D-(-)-2-amino5-phosphonopentanoate; AMPA, $\alpha$-amino-3-hydroxy-5-methyl- 
4-isoxazolepropionic acid receptor; CNQX, 6-cyano-7-nitroquinoxaline-2,3-dione; MTT, (3-[4,5-dimethylthiazol-2-yl]-2,5diphenyltetrazolium bromide); DIV, days in vitro; $\left[\mathrm{Ca}^{2+}\right]_{\mathcal{C}}$ cytosolic calcium concentration in cortical neurons

\section{REFERENCES}

(1) Sakai, R. and Swanson, G. T. (2014) Recent progress in neuroactive marine natural products. Nat. Prod. Rep. 31, 273-309.

(2) Berlinck, R. G., Braekman, J. C., Daloze, D., Bruno, I., Riccio, R., Ferri, S., Spampinato, S., and Speroni, E. (1993) Polycyclic guanidine alkaloids from the marine sponge Crambe crambe and $\mathrm{Ca}++$ channel blocker activity of crambescidin 816. J. Nat. Prod. 56, 1007-1015.

(3) Berlinck, R. G., Braekman, J. C., Daloze, D., Hallenga, K., Ottinger, R., et al. (1990) Two new guanidine alkaloids from the mediterranean sponge crambe crambe. Tetrahedron Lett. 31, 65316534 .

(4) Bondu, S., Genta-Jouve, G., Leirós, M., Vale, C., Guigonis, J.-M., Botana, L. M., and Thomas, O. P. (2012) Additional bioactive guanidine alkaloids from the Mediterranean sponge Crambe crambe. RSC Adv. 2, 2828-2835.

(5) Jares-Erijman, E. A., Ingrum, A. A., Sun, F., and Rinehart, K. L. (1993) On the structures of crambescins B and C1. J. Nat. Prod. 56, 2186-2188.

(6) Aron, Z. D., Pietraszkiewicz, H., Overman, L. E., Valeriote, F., and Cuevas, C. (2004) Synthesis and anticancer activity of side chain analogs of the crambescidin alkaloids. Bioorg. Med. Chem. Lett. 14, 3445-3449.

(7) Roel, M., Rubiolo, J. A., Guerra-Varela, J., Silva, S. B., Thomas, O. P., Cabezas-Sainz, P., Sanchez, L., Lopez, R., and Botana, L. M. (2016) Marine guanidine alkaloids crambescidins inhibit tumor growth and activate intrinsic apoptotic signaling inducing tumor regression in a colorectal carcinoma zebrafish xenograft model. Oncotarget 7, 8307183087.

(8) Roel, M., Rubiolo, J. A., Ternon, E., Thomas, O. P., Vieytes, M. R., and Botana, L. M. (2015) Crambescin C1 Exerts a Cytoprotective Effect on HepG2 Cells through Metallothionein Induction. Mar. Drugs 13, 4633-4653.

(9) Rubiolo, J. A., Lopez-Alonso, H., Roel, M., Vieytes, M. R., Thomas, O., Ternon, E., Vega, F. V., and Botana, L. M. (2014) Mechanism of cytotoxic action of crambescidin- 816 on human liverderived tumour cells. Br. J. Pharmacol. 171, 1655-1667.

(10) Martin, V., Vale, C., Bondu, S., Thomas, O. P., Vieytes, M. R., and Botana, L. M. (2013) Differential effects of crambescins and crambescidin 816 in voltage-gated sodium, potassium and calcium channels in neurons. Chem. Res. Toxicol. 26, 169-178.

(11) Martin, V., Vale, C., Antelo, A., Hirama, M., Yamashita, S., Vieytes, M. R. and Botana, L. M. (2014) Differential effects of ciguatoxin and maitotoxin in primary cultures of cortical neurons. Chem. Res. Toxicol. 27, 1387-1400.

(12) Vale, C., Gomez-Limia, B., Vieytes, M. R., and Botana, L. M. (2007) Mitogen-activated protein kinases regulate palytoxin-induced calcium influx and cytotoxicity in cultured neurons. Br. J. Pharmacol. $152,256-266$.

(13) Hartley, D. M., Kurth, M. C., Bjerkness, L., Weiss, J. H., and Choi, D. W. (1993) Glutamate receptor-induced 45Ca2+ accumulation in cortical cell culture correlates with subsequent neuronal degeneration. J. Neurosci. 13, 1993-2000.

(14) Zundorf, G., and Reiser, G. (2011) Calcium dysregulation and homeostasis of neural calcium in the molecular mechanisms of neurodegenerative diseases provide multiple targets for neuroprotection. Antioxid. Redox Signaling 14, 1275-1288.

(15) Veng, L. M., Mesches, M. H., and Browning, M. D. (2003) Agerelated working memory impairment is correlated with increases in the L-type calcium channel protein alpha1D (Cav1.3) in area CAl of the hippocampus and both are ameliorated by chronic nimodipine treatment. Mol. Brain Res. 110, 193-202.
(16) Ito, Y., and Araki, N. (2010) [Calcium antagonists: current and future applications based on new evidence. Neuroprotective effect of calcium antagonists]. Clin Calcium 20, 83-88.

(17) Paschen, W., and Doutheil, J. (1999) Disturbances of the functioning of endoplasmic reticulum: a key mechanism underlying neuronal cell injury? J. Cereb. Blood Flow Metab. 19, 1-18.

(18) Schinder, A. F., Olson, E. C., Spitzer, N. C., and Montal, M. (1996) Mitochondrial dysfunction is a primary event in glutamate neurotoxicity. J. Neurosci. 16, 6125-6133.

(19) Kortekaas, P., and Wadman, W. J. (1997) Development of HVA and LVA calcium currents in pyramidal CA1 neurons in the hippocampus of the rat. Dev. Brain Res. 101, 139-147.

(20) Uhlén, P., Fritz, N., Smedler, E., Malmersjö, S., and Kanatani, S. (2015) Calcium signaling in neocortical development. Dev. Neurobiol. $75,360-368$.

(21) Opitz, T., De Lima, A. D., and Voigt, T. (2002) Spontaneous development of synchronous oscillatory activity during maturation of cortical networks in vitro. J. Neurophysiol. 88, 2196-2206.

(22) Turrigiano, G. G. (2008) The self-tuning neuron: synaptic scaling of excitatory synapses. Cell 135, 422-435.

(23) Turrigiano, G. G., and Nelson, S. B. (2004) Homeostatic plasticity in the developing nervous system. Nat. Rev. Neurosci. 5, 97107.

(24) Martin, V., Vale, C., Hirama, M., Yamashita, S., Rubiolo, J. A., Vieytes, M. R., and Botana, L. M. (2015) Synthetic ciguatoxin CTX 3C induces a rapid imbalance in neuronal excitability. Chem. Res. Toxicol. 28, 1095-1108.

(25) Chang, L., Whittaker, N. F., and Bewley, C. A. (2003) Crambescidin 826 and dehydrocrambine A: new polycyclic guanidine alkaloids from the marine sponge Monanchora sp. that inhibit HIV-1 fusion. J. Nat. Prod. 66, 1490-1494.

(26) Lazaro, J. E., Nitcheu, J., Mahmoudi, N., Ibana, J. A., Mangalindan, G. C., Black, G. P., Howard-Jones, A. G., Moore, C. G., Thomas, D. A., Mazier, D., Ireland, C. M., Concepcion, G. P., Murphy, P. J., and Diquet, B. (2006) Antimalarial activity of crambescidin 800 and synthetic analogues against liver and blood stage of Plasmodium sp. J. Antibiot. 59, 583-590.

(27) Rubiolo, J. A., Ternon, E., Lopez-Alonso, H., Thomas, O. P., Vega, F. V., Vieytes, M. R., and Botana, L. M. (2013) Crambescidin816 acts as a fungicidal with more potency than crambescidin- 800 and -830, inducing cell cycle arrest, increased cell size and apoptosis in Saccharomyces cerevisiae. Mar. Drugs 11, 4419-4434.

(28) Gallo, V., Kingsbury, A., Balazs, R., and Jorgensen, O. S. (1987) The role of depolarization in the survival and differentiation of cerebellar granule cells in culture. J. Neurosci. 7, 2203-2213.

(29) Chang, R. C., Hudson, P. M., Wilson, B. C., Liu, B., Abel, H., and Hong, J. S. (2000) High concentrations of extracellular potassium enhance bacterial endotoxin lipopolysaccharide-induced neurotoxicity in glia-neuron mixed cultures. Neuroscience 97, 757-764.

(30) Takahashi, H., Manaka, S., and Sano, K. (1981) Changes in extracellular potassium concentration in cortex and brain stem during the acute phase of experimental closed head injury. J. Neurosurg. 55, 708-717.

(31) Schanne, F. A., Kane, A. B., Young, E. E., and Farber, J. L. (1979) Calcium dependence of toxic cell death: a final common pathway. Science 206, 700-702.

(32) Choi, D. W. (1995) Calcium: still center-stage in hypoxicischemic neuronal death. Trends Neurosci. 18, 58-60.

(33) Momeni, H. R, and Jarahzadeh, M. (2012) Effects of a voltage sensitive calcium channel blocker and a sodium-calcium exchanger inhibitor on apoptosis of motor neurons in adult spinal cord slices. Cell J. 14, 171-176.

(34) Gwag, B. J., Canzoniero, L. M., Sensi, S. L., Demaro, J. A., Koh, J. Y., Goldberg, M. P., Jacquin, M., and Choi, D. W. (1999) Calcium ionophores can induce either apoptosis or necrosis in cultured cortical neurons. Neuroscience 90, 1339-1348.

(35) Tong, J. X., Eichler, M. E., and Rich, K. M. (1996) Intracellular calcium levels influence apoptosis in mature sensory neurons after trophic factor deprivation. Exp. Neurol. 138, 45-52. 
(36) Stanika, R. I., Villanueva, I., Kazanina, G., Andrews, S. B., and Pivovarova, N. B. (2012) Comparative impact of voltage-gated calcium channels and NMDA receptors on mitochondria-mediated neuronal injury. J. Neurosci. 32, 6642-6650.

(37) Szydlowska, K., and Tymianski, M. (2010) Calcium, ischemia and excitotoxicity. Cell Calcium 47, 122-129.

(38) Santostasi, G., Kutty, R. K., Bartorelli, A. L., Yasumoto, T., and Krishna, G. (1990) Maitotoxin-induced myocardial cell injury: calcium accumulation followed by ATP depletion precedes cell death. Toxicol. Appl. Pharmacol. 102, 164-173.

(39) Koh, J. Y., and Cotman, C. W. (1992) Programmed cell death: its possible contribution to neurotoxicity mediated by calcium channel antagonists. Brain Res. 587, 233-240.

(40) Wasik, A., Kajta, M., Lenda, T., and Antkiewicz-Michaluk, L. (2014) Concentration-dependent opposite effects of 1-benzyl-1,2,3,4tetrahydroisoquinoline on markers of apoptosis: in vitro and ex vivo studies. Neurotoxic. Res. 25, 90-99.

(41) Jares-Erijman, E. A., Sakai, R., and Rinehart, K. L. (1991) Crambescidins: new antiviral and cytotoxic compounds from the sponge Crambe crambe. J. Org. Chem. 56, 5712-5715.

(42) Cino, I., and Formenti, A. (2008) Spermine biphasically affects $\mathrm{N}$-type calcium channel currents in adult dorsal root ganglion neurons of the rat. Biochim. Biophys. Acta, Biomembr. 1778, 2437-2443.

(43) Zorumski, C. F., and Thio, L. L. (1992) Properties of vertebrate glutamate receptors: calcium mobilization and desensitization. Prog. Neurobiol. 39, 295-336.

(44) Rodriguez-Garcia, M., Oliva, H., Climent, N., Escribese, M. M., Garcia, F., Moran, T. M., Gatell, J. M., and Gallart, T. (2009) Impact of alpha-defensins $1-3$ on the maturation and differentiation of human monocyte-derived DCs. Concentration-dependent opposite dual effects. Clin. Immunol. 131, 374-384.

(45) Bergmann, J., Langen, P., Thomas, Y., and Brachwitz, H. (1998) Opposite effects on cytosolic Ca2+ of antitumor phospholipids by induction of calcium influx and activation of endoplasmic reticulum Ca(2+)-ATPase. Cell Calcium 23, 241-249.

(46) Cataldi, M. (2013) The changing landscape of voltage-gated calcium channels in neurovascular disorders and in neurodegenerative diseases. Curr. Neuropharmacol 11, 276-297.

(47) Thibault, O., Gant, J. C., and Landfield, P. W. (2007) Expansion of the calcium hypothesis of brain aging and Alzheimer's disease: minding the store. Aging Cell 6, 307-317.

(48) King, A. E., Chung, R. S., Vickers, J. C., and Dickson, T. C. (2006) Localization of glutamate receptors in developing cortical neurons in culture and relationship to susceptibility to excitotoxicity. $J$. Comp. Neurol. 498, 277-294.

(49) Augustine, G. J., Charlton, M. P., and Smith, S. J. (1987) Calcium action in synaptic transmitter release. Annu. Rev. Neurosci. 10, 633-693.

(50) Martin, V., Vale, C., Rubiolo, J. A., Roel, M., Hirama, M., Yamashita, S., Vieytes, M. R., and Botana, L. M. (2015) Chronic ciguatoxin treatment induces synaptic scaling through voltage gated sodium channels in cortical neurons. Chem. Res. Toxicol. 28, 11091119.

(51) Xia, Z., Dudek, H., Miranti, C. K., and Greenberg, M. E. (1996) Calcium influx via the NMDA receptor induces immediate early gene transcription by a MAP kinase/ERK-dependent mechanism. J. Neurosci. 16, 5425-5436. 